\title{
Factors associated with intentions to use e-cigarettes among Australian young adult
}

\section{non-smokers}

\author{
Michelle I Jongenelis $^{\mathrm{a}^{*}}(\mathrm{PhD})$, Emily Brennan ${ }^{\mathrm{b}}(\mathrm{PhD})$, Terry Slevin ${ }^{\mathrm{ac}}(\mathrm{MPH})$, Caitlin \\ Kameron $^{\text {ad }}$ (LLB (Hons)), Elizabeth Jardine ${ }^{\mathrm{d}}$ (BBS), Daniel Rudaizky ${ }^{\mathrm{e}}$ (PhD), Simone \\ Pettigrew $^{\mathrm{a}}(\mathrm{PhD})$
}

\begin{abstract}
${ }^{\mathrm{a}}$ School of Psychology, Curtin University
michelle.jongenelis@curtin.edu.au (Research Fellow)

simone.pettigrew@curtin.edu.au (Research Professor)

${ }^{\mathrm{b}}$ Centre for Behavioural Research in Cancer, Cancer Council Victoria

emily.brennan@cancervic.org.au (Senior Research Fellow)
\end{abstract}

${ }^{\mathrm{c} P u b l i c ~ H e a l t h ~ A s s o c i a t i o n ~ o f ~ A u s t r a l i a ~}$

tslevin@phaa.net.au (Chief Executive Officer)

${ }^{\mathrm{d}}$ Cancer Council WA

ckameron@cancerwa.asn.au (Research Associate)

ljardine@cancerwa.asn.au (Tobacco Programs Manager)

${ }^{\text {e}}$ School of Psychological Sciences, The University of Western Australia

This is the author manuscript accepted for publication and has undergone full peer review but has not been through the copyediting, typesetting, pagination and proofreading process, which may lead to differences between this version and the Version of Record. Please cite this article as doi: 10.1111/dar.12963

This article is protected by copyright. All rights reserved. 
daniel.rudaizky@uwa.edu.au (Associate Researcher)

*corresponding author

School of Psychology, Curtin University

Kent Street, Bentley, Western Australia, Australia, 6102

+61 892665797

Conflicts of Interest: None to declare.

Running Head: Non-smokers' intentions to use e-cigarettes 


\begin{abstract}
Introduction and Aims: A growing body of evidence suggests e-cigarette use increases the risk of conventional cigarette use. Assessing the factors associated with intentions to use ecigarettes can inform programs designed to minimise uptake, potentially assisting in preventing a new population of smokers. This study developed and tested a model assessing the importance of various factors that may be associated with intentions to use e-cigarettes among young adults who have never used e-cigarettes or tobacco cigarettes.
\end{abstract}

Design and Methods: A web panel provider recruited 429 Australian 18- to 25-year-olds who had never used e-cigarettes or smoked tobacco cigarettes (56\% female, mean age $=21.17$ years). Various individual and social factors were assessed as potential direct and indirect predictors of e-cigarette use intentions.

Results: The developed model provided an excellent fit to the data and accounted for $49 \%$ of the variance in use intentions. Males had greater intentions to use e-cigarettes compared to females $(\beta=-0.13)$. Having a greater number of friends who smoke tobacco cigarettes ( $\beta=0.11)$ and curiosity about e-cigarette use $(\beta=0.58)$ were also directly associated with greater use intentions. Positive expectancies about e-cigarettes $(\beta=0.14)$, having family members who use e-cigarettes ( $\beta=0.11$ ), and having friends who smoke tobacco cigarettes ( $\beta=0.07)$ were indirectly associated with intentions via curiosity.

Discussion and Conclusions: Curiosity about e-cigarette use was strongly associated with use intentions. Aspects of the social environment were also important. Further research is needed to identify effective means of challenging positive e-cigarette expectancies given these were found to be strongly associated with intentions via curiosity.

This article is protected by copyright. All rights reserved. 
Keywords: e-cigarettes; young adults; curiosity; intentions.

This article is protected by copyright. All rights reserved. 


\section{Introduction}

Recent years have seen substantial increases in the use of e-cigarettes around the world [1-3]. For example, ever use of e-cigarettes among adults increased from 4\% in 2013 to 9\% in 2016 in Australia [3], from 7\% in 2012 to 15\% in 2017 in Europe [4, 5], and from 13\% in 2014 to 15\% in 2016 in the US [2]. Uptake of these devices has been strongest among young adults, with prevalence highest among members of this population segment relative to other age groups [1, 2, 6]. In Australia, the context of the present study, 19\% of 18- to 24-year-olds report having used an e-cigarette in their lifetime compared to $9 \%$ of all adults aged $18^{+}[3]$. For current use of e-cigarettes (defined by the Australian Institute of Health and Welfare as currently using e-cigarettes daily, weekly, or less than weekly), these figures are $7 \%$ and $4 \%$, respectively [3]. These figures should be considered in the context of the strict regulations imposed on e-cigarettes in Australia. The sale of nicotine-containing e-cigarettes is prohibited in all jurisdictions, and non-nicotine e-cigarettes are regulated in the same way as conventional cigarettes in all jurisdictions except the state of Western Australia where the sale of these devices is prohibited.

E-cigarette use may pose significant health risks, with some of the substances used in the devices found to expose users to carcinogens and heavy metals [7-12]. In addition to direct health harms, evidence indicates that e-cigarettes can serve as a gateway product to conventional tobacco use, thereby contributing to the development of a new population of smokers who are at risk of the harms associated with tobacco cigarette smoking [13-15]. For example, recent longitudinal research in young adults has found that e-cigarette use increases 
the risk of tobacco cigarette initiation among never smokers [16, 17]. The documented progression from e-cigarette use to initiation of conventional tobacco cigarette smoking indicates that minimising uptake of e-cigarettes in never smokers is important to prevent future tobacco cigarette use.

A growing body of evidence has demonstrated the influence of social norms in facilitating ecigarette use among young adults. For example, use among college students is more likely among those who have friends, family, or peers who use e-cigarettes and/or have a positive and accepting attitude to these devices [18-20]. E-cigarette use is also more likely among those who have friends who smoke conventional cigarettes [21]. These findings are consistent with various behavioural theories that consider perceptions of others' beliefs and observations of others' behaviours as important determinants of one’s own behaviour (e.g., Social Learning Theory [22]; Theory of Reasoned Action [23]).

The individual factors related to e-cigarette use in young adults that have been examined to date include gender, attitudes, and sensation seeking traits. Findings indicate that males are more likely to use e-cigarettes than females [18, 21, 24, 25]. The limited literature on young adults' attitudes as a precursor to e-cigarette use has focused predominantly on beliefs about the risk of harm of e-cigarette use [18, 26]. This research indicates that individuals who believe e-cigarettes are less harmful than conventional cigarettes are more likely than those who do not hold this belief to use the devices $[18,26]$. Some evidence is beginning to emerge on e-cigarette expectancies, with research suggesting that beliefs about the positive 
experiences associated with e-cigarette use (e.g., feeling relaxed) are linked with use of the devices [27]. Although previous research suggests that sensation seeking traits are a major correlate of drug use and conventional cigarette smoking [28, 29], just one study to date appears to have been conducted assessing the association between this individual personality trait and e-cigarette use in young adults [24]. In this study of college students, sensation seeking traits did not significantly predict use of e-cigarettes.

There are several notable gaps in the literature. First, although research assessing the factors associated with intentions to use e-cigarettes among young adults may inform the development of effective programs designed to minimise uptake of these devices in this population segment, such research is lacking. Second, research assessing curiosity about ecigarette use among young adults is needed. Curiosity is considered a critical motivational state influencing human behaviour [30]. In the context of tobacco smoking, curiosity about smoking a tobacco cigarette has been found to be an important psychological precursor to smoking initiation [31]. Furthermore, research among users of e-cigarettes has found that curiosity is retrospectively reported to be an important reason for initiating use [32-34]. Research examining the relationship between curiosity about e-cigarette use and intentions to use e-cigarettes among never users and never smokers is therefore warranted. Given previous research conducted with adolescents suggests that individual factors such as perceptions of ecigarette harm are associated with curiosity about e-cigarette use, it is also important to assess curiosity as a mediator between individual and social variables and use intentions [35].

This article is protected by copyright. All rights reserved. 
Third, several social factors relating to e-cigarette use found to be important in other population segments have yet to be examined in young adults (e.g., having parents who smoke conventional cigarettes and/or living in a household where conventional cigarettes are smoked [36-40]). Finally, the vast majority of research to date has been conducted in countries with liberal regulations on the marketing, sale, and use of e-cigarettes. Research assessing the factors associated with intentions to use e-cigarettes in more restrictive regulatory environments such as Australia is needed to identify which factors contribute to use intentions in such environments and whether these differ from those identified in countries such as the US and UK where e-cigarettes are more readily available and used.

To address these research gaps, the present study sought to identify the relative importance of various factors that are likely to be associated with intentions to use e-cigarettes among young adults who have never smoked conventional tobacco cigarettes and have never used ecigarettes. Never smokers/users were the focus of the present study as the postulated harm minimisation and cessation benefits associated with e-cigarette use [41, 42] do not apply to these individuals. Results have the potential to inform the development of effective strategies and policies aimed at reducing e-cigarette initiation among young adults.

\section{Method}

Recruitment and sample

As part of a larger study assessing e-cigarette use among Australian young adults, an ISOaccredited web panel provider recruited 429 Australian 18- to 25-year-olds who had never used e-cigarettes and had never smoked a conventional tobacco cigarette. Eligibility was 
determined based on responses to two questions assessing whether respondents had ever tried (i) tobacco cigarettes (even just one time) and (ii) e-cigarettes (even just one or two puffs). The web-panel provider (PureProfile) uses a number of strategies to maintain their database of over 350000 Australians, including Internet and radio advertising and referral programs. Panel members receive small incentives for participating in surveys. The study received ethical approval from a university Human Research Ethics Committee.

The sample comprised 56\% females, and respondents had an average age of 21.17 years (SD $=2.34$ ). Two-thirds of the sample lived in mid and high socioeconomic status (SES) neighbourhoods (low SES = 34\%, mid SES = 41\%, high SES = 25\%; calculated from respondents’ postcode using the Australian Bureau of Statistics’ Socio-Economic Indexes for Areas [43]).

\section{Measures}

The dependent variable under investigation was e-cigarette use intentions. This was assessed by asking respondents to respond to the statement: I intend to use an e-cigarette in the next 6 months on a 4-point scale of 1 (definitely not) to 4 (definitely yes) (adapted from Primack, Soneji, Stoolmiller, Fine, and Sargent [15]). Consistent with previous research [44], intentions to use e-cigarettes was treated as a continuous variable.

Independent variables - social. Perceived pressure from others regarding use of e-cigarettes and conventional cigarettes was assessed by asking respondents 10 questions: Do the 
following people or groups place any pressure on you about using [smoking] e-cigarettes [tobacco cigarettes]?, with five different social groups presented - my family, my friends, my partner (if applicable), my colleagues (if applicable), and society. Responses to each item were made on a 5-point scale of 1 (pressure me not to use) to 5 (pressure me to use). Two variables were created comprising the grand means of scores for all five groups for pressure to use (i) e-cigarettes (Cronbach's alpha $=0.92$ ) and (ii) conventional cigarettes (Cronbach's alpha $=0.96)$. To maximise the information available for analyses, the grand means of scores for respondents for whom the 'partner' and 'colleagues' items were not applicable were calculated based on responses to the applicable items.

Use of e-cigarettes and conventional cigarettes among family, friends, and those living in the respondent's home was assessed by asking: How many members of your immediate family currently use [smoke] e-cigarettes [tobacco cigarettes] (either socially or regularly)? (six response options: $0=0$ to $5=$ more than 4); How many of your four closest friends currently use [smoke] e-cigarettes [tobacco cigarettes] (either socially or regularly)? (five response options: $0=0$ to $4=4$ ); and Does anyone who lives with you now currently use [smoke] ecigarettes [tobacco cigarettes] (either socially or regularly)? (dichotomous yes or no response options) (items adapted from Barrington-Trimis et al. [45]). Perceived disapproval of e-cigarettes and tobacco cigarettes was assessed with two questions: In general, to what extent do people who are important to you disapprove of using [smoking] e-cigarettes [tobacco cigarettes]?. Responses were made on a scale of 1 (not at all) to 5 (a great deal). 
Independent variables - individual. Respondents reported on their gender and age. Beliefs relating to the harms associated with e-cigarette use were assessed with a single item that asked respondents to indicate how harmful they believe e-cigarettes are to health $(1=$ not at all harmful to 5 = very harmful). A don't know option was made available, with these responses treated as missing data. To assess general attitudes, respondents were presented with 5-point semantic differential scales and asked to rate the use of e-cigarettes on several characteristics (boring/fun, unenjoyable/enjoyable, stupid/smart, uncool/cool, unattractive/attractive), each presented in random order (adapted from Farrelly et al. [46]). A grand mean was produced, with a higher score indicative of a more favourable attitude to ecigarettes (Cronbach’s alpha $=0.96)$.

Positive expectancies were assessed by asking respondents to indicate the extent to which they agreed or disagreed with the following seven statements on a scale of 1 (strongly disagree) to 5 (strongly agree): Using e-cigarettes helps people feel more self-confident; Using e-cigarettes helps people calm down when they're feeling tense; Using e-cigarettes helps people when they're feeling angry; Using e-cigarettes makes people feel more relaxed; Using e-cigarettes cheers people up when they're in a bad mood; Using e-cigarettes helps people feel better if they've been feeling down; and Using e-cigarettes helps people think better (as per Wills, Knight, Sargent, Gibbons, Pagano, \& Williams [47] and Pokhrel, Little, Fagan, Muranaka \& Herszog [48]). For analysis purposes, a grand mean of all items was produced, with a higher score indicating more favourable expectancies about e-cigarette use (Cronbach’s alpha $=0.97)$.

This article is protected by copyright. All rights reserved. 
Sensation seeking was measured using four items adapted from the Brief Sensation Seeking Scale [49]: I like to explore strange places; I like to do frightening things; I prefer friends who are exciting and unpredictable; and I love to have new and exciting experiences, even if I have to break the rules. Responses were made on a 5-point scale $(1=$ strongly disagree to $5=$ strongly agree). A grand mean was produced, with a higher score indicative of stronger sensation seeking characteristics (Cronbach’s alpha $=0.83$ ).

Curiosity was measured by asking respondents: How curious are you about using ecigarettes?. Responses were made on a scale of 1 (not at all curious) to 5 (very curious) (adapted from Mantey, Cooper, Clendennen, Pasch, \& Perry [50]).

\section{Procedure}

The measures were administered in an online survey disseminated via the web panel provider. All respondents provided informed consent. An initial question assessed respondents' awareness of e-cigarettes, with most $(n=310,72 \%)$ reporting that they had heard of the devices. To reduce reporting error, a description of e-cigarettes was provided to all respondents.

\section{Statistical analysis}

Descriptive statistics were calculated to determine the extent to which respondents were curious about using e-cigarettes and intended to use the devices in the future. Univariate 
linear regression analyses were conducted to assess the individual and social factors associated with curiosity and intentions to use e-cigarettes. Factors that were significantly associated with either curiosity or intentions at $P<0.05$ were then combined into a multivariate mediational model in which curiosity about e-cigarette use was postulated to mediate the relationship between the assessed individual and social variables and intentions to use e-cigarettes in the next six months. This model was tested in MPlus, with the model indirect function used to assess the statistical significance of indirect effects.

\section{Results}

\section{Descriptive statistics}

Table 1 presents descriptive statistics for the independent and dependent variables under investigation. Curiosity about e-cigarette use and intentions to use the devices in the next six months were low. Just over one-quarter (28\%) of respondents reported being at all curious about the devices (i.e., selected 2, 3, 4, or 5 on a 5-point scale of $1=$ not at all curious to $5=$ very curious). Only 3\% indicated they would 'probably' or 'definitely' use an e-cigarette in the next six months.

\section{Mediational model of factors associated with intentions to use e-cigarettes}

Significant predictors emerging from the univariate analyses (presented in the online supplementary tables SI and SII) assessing the factors associated with curiosity about ecigarette use and intentions to use e-cigarettes in the next six months were combined into a multivariate mediational model. Curiosity was specified as the mediator and intentions was 
the outcome. This model provided an excellent fit to the data $\left(\chi^{2}(4)=4.08, P=0.395 ; \chi^{2} / \mathrm{df}=\right.$ 1.02, $\mathrm{CFI}=1.00 ; \mathrm{TLI}=1.00, \mathrm{RMSEA}=0.01(95 \%$ confidence interval $=0.00,0.08), \mathrm{SRMR}$ $=0.02$ ) and accounted for $49 \%$ of the variance in intentions.

Unstandardised and standardised parameter estimates are presented in Table 2 and a schematic of the model showing significant direct effects is presented in Figure 1. Few variables were found to be directly associated with intentions to use e-cigarettes. Of these, the strongest parameter estimates were observed for curiosity, followed by gender (males reported greater intention to use e-cigarettes than did females) and then having a larger number of friends who smoke tobacco cigarettes.

Several variables were found to be indirectly associated with use intentions via curiosity (Table 3). Specifically, greater belief in the positive outcomes of e-cigarette use, having a larger number of family members who use e-cigarettes, and having a larger number of friends who smoke tobacco cigarettes were associated with greater curiosity about e-cigarette use, which in turn resulted in greater intentions to use the devices.

\section{Discussion}

The present study developed and tested a multivariate model assessing the relative importance of various factors that may be associated with intentions to use e-cigarettes among Australian young adult never smokers. Results have the potential to inform (i) the development of effective strategies to reduce e-cigarette initiation in this population segment 
and (ii) public health policy globally. The developed model was robust, accounting for a substantial proportion of the variance in e-cigarette use intentions.

Three variables were found to be directly associated with e-cigarette use intentions: curiosity about use, gender (being male), and having a larger number of friends who smoke conventional tobacco cigarettes. Of these variables, curiosity about e-cigarette use was found to be the most strongly associated with intentions to use the devices in the future, supporting previous research in the context of tobacco cigarette smoking [31, 51]. Given just over onequarter of young adult never users and never smokers in this Australian sample reported any curiosity about using e-cigarettes, the results indicate that a substantial minority of young adults are potentially at risk of initiation of use.

Three variables were found to be associated with use intentions via curiosity: positive expectancies about e-cigarettes, having a larger number of family members who use ecigarettes, and having a larger number of friends who smoke conventional tobacco cigarettes. Of these, positive expectancies were found to be the most important, consistent with previous research on the factors associated with e-cigarette use [27, 48]. Given previous research on the effects of e-cigarette advertising among young adult non-smokers has shown that positive portrayals of e-cigarettes result in more favourable attitudes to the devices [52], maintaining existing regulations on the marketing of e-cigarettes in Australia and other countries with similarly restrictive regulatory environments (e.g., Canada) should be prioritised in control efforts [53]. In countries with liberal regulations on the marketing of e-cigarettes (e.g., the US 
and the UK), policymakers should consider introducing laws that subject e-cigarettes to the same marketing restrictions that apply to conventional cigarettes [54]. These restrictions may constitute a means of reducing youth exposure to the favourable claims made by the vaping industry about their products.

The strong direct and indirect associations between various social variables and intentions to use e-cigarettes are consistent with behavioural theories that emphasise the importance of social norms [23], and support previous research in the context of e-cigarette use indicating that the social environment is an important determinant of intentions to use e-cigarettes among young adults [21]. Prior recommendations for a social norms approach to initiation prevention are therefore supported [55]. For example, campaigns could be implemented that focus on the social undesirability of vaping and peer disapproval of this behaviour. Such an approach has been found to be a potentially effective means of preventing tobacco cigarette smoking [56], and may therefore constitute a means of preventing initiation of e-cigarette use. Maintaining existing regulations in countries that restrict the marketing, sale, and use of e-cigarettes and tightening regulations in those that do not are also likely to be important in ensuring e-cigarette use is not normalised among influential family and peer groups.

Despite evidence suggesting that sensation seeking traits are a major correlate of drug use and conventional cigarette smoking [28, 29], these traits were not found to be associated with curiosity about or intentions to use e-cigarettes in the present study. This null finding is consistent with previous research in a study of college students that found sensation seeking 
traits did not significantly predict use of e-cigarettes [24]. Such traits may be more relevant in explaining the risk behaviours of adolescents than young adults.

\section{Limitations}

There were several limitations to the present study. First, the cross-sectional design means causality cannot be established. In particular, it is possible that reciprocal relationships exist between some of the independent and outcome variables. For example, although use intentions may be influenced by positive expectancies, it is also possible that use intentions may increase positive expectancies as these young adults who have never smoked cigarettes or used e-cigarettes attempt to reduce any cognitive dissonance associated with their intentions to try e-cigarettes. Further research using longitudinal designs is required to verify the direct and indirect associations observed in this study. Second, as an online web panel provider was commissioned to recruit respondents and varied methods were used to disseminate the survey link, response rates could not be determined. Given the absence of representative data that provide the demographic characteristics of the population segment from which the target sample was drawn (i.e., 18- to 25-year-old never smokers and never users of e-cigarettes), the extent to which the present results can be generalised is unknown.

Third, although the tested model accounted for a substantial proportion of the variance in use intentions, there are other variables that may be associated with intentions that were not examined. For example, recent qualitative research conducted with college students indicates that perceived behavioural control over e-cigarette use may be an important variable to 
consider in future research [57]. Fourth, few respondents reported intending to try e-cigarettes in the next six months, limiting the variability of scores on the use intentions variable.

Finally, this study was conducted in Australia, a country with some of the most restrictive ecigarette policies in the world [58]. Care should thus be taken in generalising these findings to other contexts in which e-cigarettes are more heavily promoted and readily available.

\section{Conclusion}

The present study identified several factors that could be the focus of efforts to minimise uptake of e-cigarettes among young adult never smokers. Of these, curiosity about e-cigarette use was found to have the strongest association with use intentions, suggesting that efforts to minimise uptake may need to focus on reducing curiosity and that surveillance studies could consider measuring curiosity as a potential early indicator of e-cigarette initiation. Given positive e-cigarette expectancies were found to have the strongest association with curiosity and were indirectly associated with use intentions via this variable, further research is needed to identify the source of these expectancies and identify effective means of challenging such beliefs. Maintaining current regulation of e-cigarettes in Australia to ensure e-cigarette use is not normalised may constitute an effective approach to minimising uptake.

\section{Acknowledgements}

\section{Role of Funding Sources}

This work was supported by the Western Australian Health Promotion Foundation

(Healthway), research grant \#24335. The funding source had no involvement in study design; 
in the collection, analysis and interpretation of data; in the writing of the report; and in the decision to submit the article for publication.

This article is protected by copyright. All rights reserved. 


\section{References}

1. Office for National Statistics. E-cigarette use in Great Britain. 2018.

2. Bao W, Xu G, Lu J, Snetselaar LG, Wallace RB. Changes in electronic cigarette use among adults in the United States, 2014-2016. JAMA. 2018;319(19):2039-41.

3. Australian Institute of Health and Welfare. National Drug Strategy Household Survey 2016, online data tables. Canberra: AlHW; 2017.

4. Filippidis FT, Laverty AA, Gerovasili V, Vardavas $\mathrm{Cl}$. Two-year trends and predictors of ecigarette use in 27 European Union member states. Tob Control. 2017;26(1):98-104.

5. Laverty AA, Filippidis $\mathrm{FT}$, Vardavas $\mathrm{Cl}$. Patterns, trends and determinants of e-cigarette use in 28 European Union Member States 2014-2017. Prev Med. 2018;116:13-8.

6. Jaber RM, Mirbolouk M, DeFilippis AP, Maziak W, Keith R, Payne T, et al. Electronic cigarette use prevalence, associated factors, and pattern by cigarette smoking status in the United States from NHANES (National Health and Nutrition Examination Survey) 2013-2014. J Am Heart Assoc. 2018;7(14):e008178.

7. Aherrera A, Olmedo P, Grau-Perez M, Tanda S, Goessler W, Jarmul S, et al. The association of e-cigarette use with exposure to nickel and chromium: A preliminary study of non-invasive biomarkers. Environ Res. 2017;159:313-20.

8. Behar RZ, Wang Y, Talbot P. Comparing the cytotoxicity of electronic cigarette fluids, aerosols and solvents. Tob Control. 2018;27(3):325-33.

9. Klager S, Vallarino J, MacNaughton P, Christiani DC, Lu Q, Allen JG. Flavoring chemicals and aldehydes in e-cigarette emissions. Environ Sci Technol. 2017;51(18):10806-13.

10. Kosmider L, Sobczak A, Fik M, Knysak J, Zaciera M, Kurek J, et al. Carbonyl compounds in electronic cigarette vapors: Effects of nicotine solvent and battery output voltage. Nicotine Tob Res. 2014;16(10):1319-26.

11. Chivers E, Janka M, Franklin P, Mullins B, Larcombe A. Nicotine and other potentially harmful compounds in "nicotine-free" e-cigarette liquids in Australia. Med J Aust. 2019.

12. Sassano MF, Davis ES, Keating JE, Zorn BT, Kochar TK, Wolfgang MC, et al. Evaluation of eliquid toxicity using an open-source high-throughput screening assay. PLoS Biol. 2018;16(3).

13. Bunnell RE, Agaku IT, Arrazola RA, Apelberg BJ, Caraballo RS, Corey CG, et al. Intentions to smoke cigarettes among never-smoking US middle and high school electronic cigarette users: National Youth Tobacco Survey, 2011-2013. Nicotine Tob Res. 2015;17(2):228-35.

14. Leventhal AM, Strong DR, Kirkpatrick MG, Unger JB, Sussman S, Riggs NR, et al. Association of electronic cigarette use with initiation of combustible tobacco product smoking in early adolescence. J Am Med Assoc. 2015;314(7):700-7.

15. Primack BA, Soneji S, Stoolmiller M, Fine MJ, Sargent JD. Progression to traditional cigarette smoking after electronic cigarette use among us adolescents and young adults. JAMA Pediatr. 2015;169(11):1018-23.

16. Loukas A, Marti CN, Cooper M, Pasch KE, Perry CL. Exclusive e-cigarette use predicts cigarette initiation among college students. Addict Behav. 2018;76:343-7.

17. Primack BA, Shensa A, Sidani JE, Hoffman BL, Soneji S, Sargent JD, et al. Initiation of traditional cigarette smoking after electronic cigarette use among tobacco-naïve US young adults. Am J Med. 2018;131(4):443.e1-.e9.

18. Lotrean LM. Use of electronic cigarettes among Romanian university students: A crosssectional study. BMC Public Health. 2015;15. 
19. Trumbo CW, Kim SJ. The effect of electronic cigarette advertising on intended use among college students. Addict Behav. 2015;46:77-81.

20. Agarwal D, Loukas A, Perry CL. Examining college students' social environment, normative beliefs, and attitudes in subsequent initiation of electronic nicotine delivery systems. Health Educ Behav. 2018;45(4):532-9.

21. Choi K, Forster J. Characteristics associated with awareness, perceptions, and use of electronic nicotine delivery systems among young US Midwestern adults. Am J Public Health. 2013;103(3):556-61.

22. Bandura A. Social learning theory. Englewood Cliffs, N.J.: Prentice Hall; 1977.

23. Fishbein $\mathrm{M}$, Ajzen I. Belief, attitude, intention, and behavior: An introduction to theory and research. Reading, Mass.: Addison-Wesley Pub. Co.; 1975.

24. Sutfin EL, McCoy TP, Morrell HE, Hoeppner BB, Wolfson M. Electronic cigarette use by college students. Drug Alcohol Depend. 2013;131(3):214-21.

25. Czoli CD, Hammond D, White CM. Electronic cigarettes in Canada: prevalence of use and perceptions among youth and young adults. Can J Public Health. 2014;105(2):97.

26. Choi K, Forster JL. Beliefs and experimentation with electronic cigarettes: A prospective analysis among young adults. Am J Prev Med. 2014;46(2):175-8.

27. Pokhrel P, Lam TH, Pagano I, Kawamoto CT, Herzog TA. Young adult e-cigarette use outcome expectancies: Validity of a revised scale and a short scale. Addict Behav. 2018;78:193-9.

28. Zuckerman M, Ball S, Black J. Influences of sensation seeking, gender, risk appraisal, and situational motivation on smoking. Addict Behav. 1990;15(3):209-20.

29. Kelly AB, O'Flaherty M, Connor JP, Homel R, Toumbourou JW, Patton GC, et al. The influence of parents, siblings and peers on pre-and early-teen smoking: A multilevel model. Drug and Alcohol Review. 2011;30(4):381-7.

30. Loewenstein G. The psychology of curiosity: A review and reinterpretation. Psychol Bull. 1994;116(1):75-98.

31. Pierce JP, Distefan JM, Kaplan RM, Gilpin EA. The role of curiosity in smoking initiation. Addict Behav. 2005;30(4):685-96.

32. Kong G, Morean ME, Cavallo DA, Camenga DR, Krishnan-Sarin S. Reasons for electronic cigarette experimentation and discontinuation among adolescents and young adults. Nicotine Tob Res. 2015;17(7):847-54.

33. Schmidt L, Reidmohr A, Harwell TS, Helgerson SD. Prevalence and reasons for initiating use of electronic cigarettes among adults in Montana, 2013. Prev Chronic Dis. 2014;11:E204.

34. Biener L, Song E, Sutfin EL, Spangler J, Wolfson M. Electronic cigarette trial and use among young adults: Reasons for trial and cessation of vaping. Int J Environ Res Public Health.

2015;12(12):16019-26.

35. Margolis KA, Nguyen AB, Slavit WI, King BA. E-cigarette curiosity among US middle and high school students: Findings from the 2014 National Youth Tobacco Survey. Prev Med. 2016;89(1-6).

36. Cardenas VM, Breen PJ, Compadre CM, Delongchamp RR, Barone CP, Phillips MM, et al. The smoking habits of the family influence the uptake of e-cigarettes in US children. Ann Epidemiol. 2015;25(1):60-2.

37. Hanewinkel R, Isensee B. Risk factors for e-cigarette, conventional cigarette, and dual use in German adolescents: A cohort study. Prev Med. 2015;74:59-62. 
38. Lippert AM. Do adolescent smokers use e-cigarettes to help them quit? The sociodemographic correlates and cessation motivations of U.S. adolescent e-cigarette use. Am J Health Promot. 2015;29(6):374-9.

39. Xiao L, Parascandola M, Wang C, Jiang Y. Perception and current use of e-cigarettes among youth in China. Nicotine Tob Res. 2018.

40. Zhang X, Pu J. E-cigarette use among US adolescents: Secondhand smoke at home matters. Int J Public Health. 2016;61(2):209-13.

41. Abrams DB, Glasser AM, Pearson JL, Villanti AC, Collins LK, Niaura RS. Harm minimization and tobacco control: Reframing societal views of nicotine use to rapidly save lives. Annu Rev Public Health. 2018;39:193-213.

42. Levy DT, Borland R, Lindblom EN, Goniewicz ML, Meza R, Holford TR, et al. Potential deaths averted in USA by replacing cigarettes with e-cigarettes. Tob Control. 2018;27(1):18-25.

43. Australian Bureau of Statistics. Census of Population and Housing: Socio-Economic Indexes for Areas (SEIFA), Australia, 2016 Canberra: ABS; 2018.

44. Ma BH, Yong HH, Borland R, McNeill A, Hitchman SC. Factors associated with future intentions to use personal vaporisers among those with some experience of vaping. Drug and Alcohol Review. 2018;37(2):216-25.

45. Barrington-Trimis JL, Urman R, Berhane K, Unger JB, Cruz TB, Pentz MA, et al. E-cigarettes and future cigarette use. Pediatrics. 2016;138(1).

46. Farrelly MC, Duke JC, Crankshaw EC, Eggers ME, Lee YO, Nonnemaker JM, et al. A randomized trial of the effect of e-cigarette TV advertisements on intentions to use e-cigarettes. Am J Prev Med. 2015;49(5):686-93.

47. Wills TA, Knight R, Williams RJ, Pagano I, Sargent JD. Risk factors for exclusive e-cigarette use and dual e-cigarette use and tobacco use in adolescents. Pediatrics. 2015;135(1):e43-51.

48. Pokhrel P, Little MA, Fagan P, Muranaka N, Herzog TA. Electronic cigarette use outcome expectancies among college students. Addict Behav. 2014;39(6):1062-5.

49. Hoyle R, Stephenson M, Palmgreen P, Lorch E, Donohew R. Reliability and validity of a brief measure of sensation seeking. Pers Individ Dif. 2002;32:401-14.

50. Mantey DS, Cooper MR, Clendennen SL, Pasch KE, Perry CL. E-cigarette marketing exposure is associated with e-cigarette use among US youth. J Adolesc Health. 2016;58(6):686-90.

51. Nodora J, Hartman SJ, Strong DR, Messer K, Vera LE, White MM, et al. Curiosity predicts smoking experimentation independent of susceptibility in a US national sample. Addict Behav. 2014;39(12):1695-700.

52. Pokhrel P, Fagan P, Herzog TA, Chen Q, Muranaka N, Kehl L, et al. E-cigarette advertising exposure and implicit attitudes among young adult non-smokers. Drug Alcohol Depend.

2016;163:134-40.

53. Pokhrel P, Fagan P, Herzog TA, Laestadius L, Buente W, Kawamoto CT, et al. Social media ecigarette exposure and e-cigarette expectancies and use among young adults. Addict Behav. 2018;78:51-8.

54. Glantz SA, Bareham DW. E-cigarettes: Use, effects on smoking, risks, and policy implications. Annu Rev Public Health. 2018;39:215-35.

55. Noland M, Ickes MJ, Rayens MK, Butler K, Wiggins AT, Hahn EJ. Social influences on use of cigarettes, e-cigarettes, and hookah by college students. J Am Coll Health. 2016;64(4):319-28.

56. Brennan E, Gibson LA, Kybert-Momjian A, Liu J, Hornik RC. Promising themes for antismoking campaigns targeting youth and young adults. Tobacco Regulatory Science. 2017;3(1):29-46. 
57. Katz SJ, Erkinnen M, Lindgren B, Hatsukami D. Beliefs about e-cigarettes: A focus group study with college students. Am J Health Behav. 2019;43(1):76-87.

58. Greenhalgh EM, Grace C, Scollo MM. InDepth 18B: Electronic cigarettes (e-cigarettes), Section 18B.9 International regulatory overview. 2019. In: Tobacco in Australia: Facts and issues [Internet]. Melbourne: Cancer Council Victoria. Available from:

www.tobaccoinaustralia.org.au/chapter-18-harm-reduction/indepth-18b-e-cigarettes/18b-9regulatory-overview. 


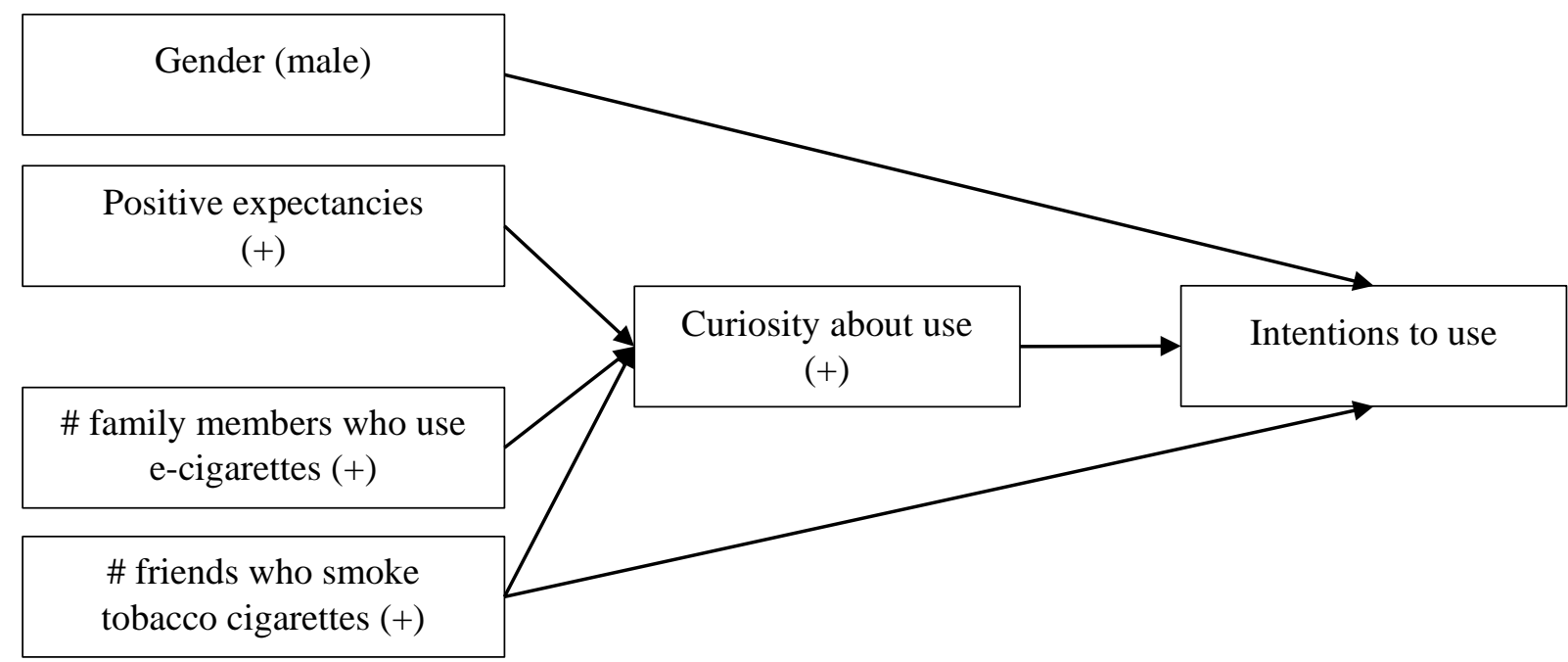

Figure 1. Schematic of the significant direct associations observed in the tested model. A '+' sign indicates a positive relationship between variables. 
Table 1. Descriptive statistics for the independent and dependent variables under investigation

$\mathrm{M}(S D)$ Scale range

\section{Independent variables}

Individual

Sensation seeking

$2.91(0.85)$

$1-5$

Positive e-cigarette expectancies

$2.60(0.97)$

$1-5$

Perceived harm associated with e-cigarettes

$3.59(1.26)$

$1-5$

General attitude to e-cigarettes

$2.31(1.17)$

$1-5$

Social

Social pressure to use e-cigarettes

$2.43(0.86)$

$1-4$

Social disapproval of e-cigarettes

$1-5$

\# family members using e-cigarettes

$0.14(0.50)$

$0-5$

\# friends using e-cigarettes

$0.18(0.60)$

$0-4$

Lives with someone who uses e-cigarettes (\% yes)

4

n/a

Social pressure to smoke cigarettes

$2.25(0.85)$

$1-4$

Social disapproval of cigarettes

$3.90(1.28)$

$1-5$

\# family members who smoke cigarettes

$0.61(1.09)$

$0-5$

\# friends who smoke cigarettes

$0.52(0.89)$

$0-4$

Lives with someone who smokes cigarettes (\% yes)

18

n/a

\section{Dependent variables}

Curiosity about e-cigarette use

$1.53(0.99)$

$1-5$

Intentions to use e-cigarettes

$1.21(0.50)$

$1-4$

$\mathrm{M}=$ Mean, $S D=$ standard deviation, $\mathrm{n} / \mathrm{a}=$ not applicable. 
This article is protected by copyright. All rights reserved. 
Table 2. Unstandardised and standardised parameter estimates from the tested model

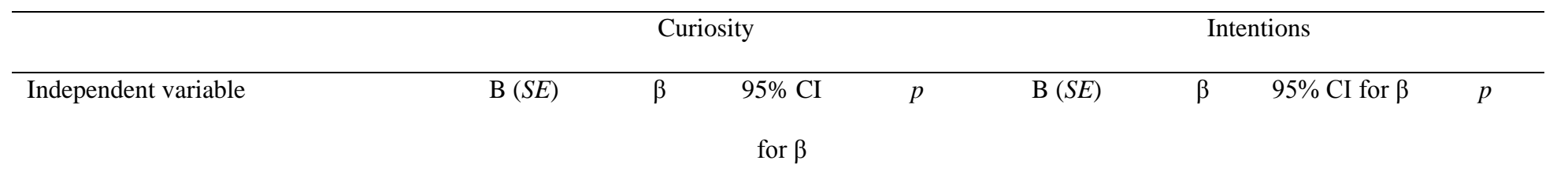

\section{Individual}

Gender ( 0 = male, 1 = female $)$

Sensation seeking

Positive e-cigarette expectancies

$\begin{array}{ll}0.24(\mathbf{0 . 0 6}) & \mathbf{0 . 2 5}\end{array}$

Perceived harm associated with e-cigs

$-0.02(0.04)$

$-0.02$

$0.05(0.05)$

0.06

$\begin{array}{cccc}0.05(0.06) & 0.05 & -0.05,0.15 & 0.371 \\ - & - & - & -\end{array}$

$0.03(0.02) \quad 0.05$

$-0.05,0.11$

0.202

Social pressure to use e-cigs

Social disapproval of e-cigs

\# family members using e-cigs

0.19

0.07, 0.32

0.002

$-0.05(0.05)$

$-0.06$

$-0.16,0.04$

0.253

\# friends using e-cigs

$-0.02(0.10)$

$-0.01$

$-0.14,0.12 \quad 0.872$

$0.07(0.04) \quad 0.09$

$0.02,0.24$

0.090

Lives with someone who uses e-cigs

Social pressure to smoke cigarettes

Social disapproval of cigarettes

\# family members who smoke

$\begin{array}{cccccccc}- & - & - & - & 0.15(0.11) & 0.06 & -0.03,0.13 & 0.175 \\ - & - & - & - & - & - & - & - \\ - & - & - & - & -0.03(0.02) & -0.08 & -0.16,0.00 & 0.063 \\ 0.07(0.05) & 0.07 & -0.03,0.17 & 0.162 & 0.02(0.02) & 0.04 & -0.05,0.12 & 0.346\end{array}$

cigarettes

\# friends who smoke cigarettes

$0.13(0.06)$

0.12

$0.01,0.22$

0.033

$0.06(0.02)$

0.11

$-0.01,0.16$

0.019

Lives with someone who smokes cigarettes

\section{Mediator}

Curiosity about e-cigarette use

$-\quad-\quad-\quad \quad-\quad 0.28(0.02)$

0.58

$0.31,0.53<0.001$

Significant results presented in bold. Number of observations in the model $=337$. A dash indicates the effect was not tested as the individual or social variable of interest was not 
found to be correlated with the dependent variable (i.e., curiosity or intentions) in univariate analyses. $\mathrm{B}=$ unstandardised regression coefficient, $S E=$ standard error, $\beta=$ standardised regression coefficient.

This article is protected by copyright. All rights reserved. 
Table 3. Unstandardised and standardised parameter estimates for the indirect effects observed in the tested model

Curiosity

Independent variable

$\mathrm{B}(S E) \quad \beta \quad p$

Individual

Gender ( 0 = male, 1 = female $)$

Sensation seeking

$0.02(0.02) \quad 0.04 \quad 0.147$

Positive e-cigarette expectancies

$0.07(0.02) \quad 0.14<0.001$

Perceived harm associated with e-cigarettes

$\begin{array}{lll}-0.01(0.01) & -0.01 \quad 0.638\end{array}$

General attitudes to e-cigarettes

$0.01(0.01) \quad 0.04 \quad 0.262$

\section{Social}

Social pressure to use e-cigarettes

$0.01(0.02) \quad 0.03 \quad 0.372$

Social disapproval of e-cigarettes

\# family members using e-cigarettes

$0.10(0.03) \quad 0.11 \quad 0.003$

\# friends using e-cigarettes

$-0.01(0.03) \quad-0.01 \quad 0.872$

Lives with someone who uses e-cigarettes

Social pressure to smoke cigarettes

Social disapproval of cigarettes

\# family members who smoke cigarettes

$0.02(0.01) \quad 0.04 \quad 0.164$

\# friends who smoke cigarettes

$0.04(0.02) \quad 0.07 \quad 0.035$

Lives with someone who smokes cigarettes

This article is protected by copyright. All rights reserved. 
Significant results presented in bold. A dash indicates the indirect effect was not tested as the individual or social variable of interest was not found to be correlated with the mediator (i.e., curiosity). $\mathrm{B}=$ unstandardised regression coefficient, $S E=$ standard error, $\beta=$ standardised regression coefficient.

This article is protected by copyright. All rights reserved. 
Dear Professor Livingston,

Thank you for the opportunity to revise our manuscript "Factors associated with intentions to use ecigarettes among Australian young adult non-smokers" (CDAR-2019-0054) according to the reviewers' helpful suggestions. The table below outlines the changes that have been made to the manuscript in response to each comment. New text added to the manuscript is shown in italics within the table.

We hope we have addressed the comments to your satisfaction, but please do not hesitate to advise if further changes are required.

Best wishes,

The authors 


\section{Reviewer 1}

. This is a very relevant paper that can inform policy globally. The research findings have at least two important policy implications. One is the importance of positive expectancies in the formation of curiosity and the role of advertising in forming these expectancies. This strongly suggests current bans on marketing of e-cigarettes in Australia and elsewhere [see https://tobaccocontrol.bmj.com/content/26/4/440 and http://globaltobaccocontrol.org/e-cigarette/country-laws-regulating-e-cigarettes] should be maintained. The authors should make reference to the potential global applicability of this finding to other countries (with or without restrictions on advertising or promotion).

2. The second is the important role that social norms (e.g., other people using ecigarettes) play in determining intention to use e-cigarettes. The authors rightly draw the conclusion that maintaining current restrictions on the sale and use of e-cigarettes will prevent the social normalization of their use - and will thus minimize intention to use, and ultimately use of e-cigarettes. Again the authors should make reference of the relevance of this finding to other countries which maintain restrictions on the sale and use of e-cigarettes

\section{Reviewer 2}

3. This paper covers an area of emerging policy interest and research growth. The paper is well written and the research methodology is sound. The manuscript would benefit from a few additional details, as per the points below, as well as further discussion of the practical implications of the research so its benefit to practice and policy is clear.
Thank you for this positive feedback. The following now appears in the manuscript to highlight the relevance of the paper to public health policy globally.

Pg 12: Results have the potential to inform (i) the development of effective strategies to reduce e-cigarette initiation in this population segment and (ii) public health policy globally.

Pg 13: Given previous research on the effects of e-cigarette advertising among young adult non-smokers has shown that positive portrayals of ecigarettes result in more favourable attitudes to the devices [53], maintaining existing regulations on the marketing of e-cigarettes in Australia and other countries with similarly restrictive regulatory environments (e.g., Canada) should be prioritised in control efforts [54]. In countries with liberal regulations on the marketing of $e$ cigarettes (e.g., the US and the UK), policymakers should consider introducing laws that subject e-cigarettes to the same marketing restrictions that apply to conventional cigarettes [55]. These restrictions may constitute a means of reducing youth exposure to the favourable claims made by the vaping industry about their products.

The following now appears in the manuscript, making reference to the relevance of the results to other countries:

Pg 14: Maintaining existing regulations in countries that restrict the marketing, sale, and use of e-cigarettes and tightening regulations in those that do not are also likely to be important in ensuring e-cigarette use is not normalised among influential family and peer groups.

Thank you for this positive feedback. We hope our changes (outlined

below) address these comments to your satisfaction. 
4. Abstract - suggest adding data to the abstract so it is more informative.

5. Introduction (page 4, line 6) - suggest adding data to support and illustrate statement that "Recent years have seen substantial increases in the use of e-cigarettes around the world".

6. Introduction (page 6, line 45) - suggest naming countries, including Australia, when you refer to countries with a "more restrictive regulative environment" and provide a brief description of what this means in terms of availability, particularly for young adults. This is important to provide context and to revisit this in your discussion.
Beta values for the factors found to be significantly associated with

intentions to use e-cigarettes have now been added to the abstract. Minor changes have been made to the abstract to accommodate these additions and ensure the abstract remains within the word limit.

Pg 3: The developed model provided an excellent fit to the data and accounted for $49 \%$ of the variance in use intentions. Males had greater intentions to use e-cigarettes compared to females $(\beta=-0.13)$. Having a greater number of friends who smoke tobacco cigarettes $(\beta=0.11)$ and curiosity about e-cigarette use $(\beta=0.58)$ were also directly associated with greater use intentions. Positive expectancies about e-cigarettes ( $\beta=0.14)$, having family members who use e-cigarettes $(\beta=0.11)$, and having friends who smoke tobacco cigarettes $(\beta=0.07)$ were indirectly associated with intentions via curiosity.

Data supporting this statement has now been added to the manuscript:

Pg 4: Recent years have seen substantial increases in the use of ecigarettes around the world [1-3]. For example, ever use of e-cigarettes among adults increased from 4\% in 2013 to 9\% in 2016 in Australia [3], from 7\% in 2012 to 15\% in 2017 in Europe [4, 5], and from 13\% in 2014 to $15 \%$ in 2016 in the US [2].

Australia is now explicitly mentioned in the relevant section of the paper:

Pg 6: Research assessing the factors associated with intentions to use ecigarettes in more restrictive regulatory environments such as Australia is needed to identify which factors contribute to use intentions in such environments and whether these differ from those identified in countries such as the US and UK where e-cigarettes are more readily available and used.

A description of Australia's regulatory environment is now provided:

Pg 4: In Australia, the context of the present study, $19 \%$ of 18 - to 24 - 
8. Methods (page 10, line 29) - it is mentioned that $72 \%$ of participants reported that they had heard of e-cigarettes, which I'm assuming meant that $28 \%$ hadn't. Did the authors consider these potential subgroups in their analysis in order to assess if factors associated with intention to use e-cigarettes differed for these two groups?

9. Results - there is no description of the sample provided in the results, only a brief breakdown of male/female and age in the methods. Was additional information collected on the demographics of the sample, which would allow the representativeness of the sample to be determined? At this stage it is unclear how representative the sample is of young people in this age group and therefore if the results can be generalized further. If additional data are not available, this is a limitation that needs to be discussed. If these data are available, did the authors consider weighting the sample to maximize representativeness?
We have now conducted analyses examining differences according to awareness of e-cigarettes. Awareness was not found to be associated with any of the dependent variables under investigation. These results have been added to Supplementary Tables SI and SII.

Information was collected on respondents' socioeconomic status. This is now reported in the manuscript as follows:

Pg 7: The sample comprised $56 \%$ females, and respondents had an average age of 21.17 years $(S D=2.34)$. Two-thirds of the sample lived in mid and high socioeconomic status (SES) neighbourhoods (low SES $=34 \%$, mid SES $=41 \%$, high SES $=25 \%$; calculated from respondents' postcode using the Australian Bureau of Statistics' Socio-Economic Indexes for Areas [44]).

There is an absence of representative data that provide the demographic characteristics of the population segment from which the target sample was drawn (i.e., 18- to 25-year-old never smokers and never users of e-

cigarettes). As such, we are unable to determine sample representativeness. We have now discussed this in the limitations section of the manuscript as follows:

Pg 15: Second, as an online web panel provider was commissioned to recruit respondents and varied methods were used to disseminate the survey link, response rates could not be determined. Given the absence of representative data that provide the demographic characteristics of the population segment from which the target sample was drawn (i.e., 18- to 25-year-old never smokers and never users of e-cigarettes), the extent to which the present results can be generalised is unknown.

The sample was not weighted as weighting has been shown to increase bias in non-probability-based samples (Gittelman et al., 2015). 
10. Results - did the authors look at whether the results differed according to age? i.e., was there any difference by age within the $18-24$ year olds?

\section{Reference:}

Gittelman, S. H., Thomas, R. K., Lavrakas, P. J., \& Lange, V. (2015). Quota controls in survey research: A test of accuracy and intersource reliability in online samples. Journal of Advertising Research, 55(4), 368.

We have now run analyses examining age differences. This demographic factor was not significantly associated with any of the dependent variables in univariate analyses and was therefore not included in the multivariate model. Results from the univariate analyses have been added to Supplementary Tables SI and SII.

11. Discussion (page 13, line 10) - the authors mention that there is a need to "....identify effective means of challenging such beliefs." It would be beneficial to expand on this with some examples of what these "means" might be in order to demonstrate the potential that such beliefs could be modified. This will help to better justify the need for this study by demonstrating the practical implications of the results.

\section{The discussion has been expanded upon as follows:}

Pg 13: Of these, positive expectancies were found to be the most important, consistent with previous research on the factors associated with e-cigarette use [27, 49]. Given previous research on the effects of e-cigarette advertising among young adult non-smokers has shown that positive portrayals of e-cigarettes result in more favourable attitudes to the devices [53], maintaining existing regulations on the marketing of $e$ cigarettes in Australia and other countries with similarly restrictive regulatory environments (e.g., Canada) should be prioritised in control efforts [54]. In countries with liberal regulations on the marketing of ecigarettes (e.g., the US and the UK), policymakers should consider introducing laws that subject e-cigarettes to the same marketing restrictions that apply to conventional cigarettes [55]. These restrictions may constitute a means of reducing youth exposure to the favourable claims made by the vaping industry about their products.

12. Discussion (page 13, line 35) - the authors state that “... prior recommendations for a social norms approach to initiation prevention are therefore supported" - again, it would be good to further translate this into what this social norms approach would look like in terms of policy or practice.

The discussion to which you refer has been expanded upon as follows:

Pg 14: Prior recommendations for a social norms approach to initiation prevention are therefore supported [56]. For example, campaigns could be implemented that focus on the social undesirability of vaping and peer disapproval of this behaviour. Such an approach has been found to

This article is protected by copyright. All rights reserved. 
be a potentially effective means of preventing tobacco cigarette smoking

[57], and may therefore constitute a means of preventing initiation of ecigarette use. Maintaining existing regulations in countries that restrict the marketing, sale, and use of e-cigarettes and tightening regulations in those that do not are also likely to be important in ensuring e-cigarette use is not normalised among influential family and peer groups. 


\section{University Library}

\section{- M M N E R VA A gateway to Melbourne's research publications}

Minerva Access is the Institutional Repository of The University of Melbourne

\section{Author/s:}

Jongenelis, M;Brennan, E;Slevin, T;Kameron, C;Jardine, E;Rudaizky, D;Pettigrew, S

Title:

Factors associated with intentions to use e-cigarettes among Australian young adult nonsmokers

Date:

2019-07-01

\section{Citation:}

Jongenelis, M., Brennan, E., Slevin, T., Kameron, C., Jardine, E., Rudaizky, D. \& Pettigrew, S. (2019). Factors associated with intentions to use e-cigarettes among Australian young adult non-smokers. DRUG AND ALCOHOL REVIEW, 38 (5), pp.579-587. https://doi.org/10.1111/ dar.12963.

Persistent Link:

http://hdl.handle.net/11343/286099 